Keywords: Jiaoyufication; Gentrification; Space Reproduction; Cultural Reproduction; Class Remaking; social polarization, Nanjing, China

$<$ INSERT FIRST PAGE HEADER AND COPYRIGHT LINE>

$<O N$ SUBSEQUENT PAGES INSERT RUNNING HEADLINE: L.H. = EDENSOR, WU AND CHENG R.H. = BEYOND SPACE>

\title{
<ATL>BEYOND SPACE: Spatial (Re)production and Middle-Class Remaking Driven by Jiaoyufication in Nanjing City, China</ATL>
}

\section{$<A U>$ TIM EDENSOR, QIYAN WU AND JIANQUAN CHENG <|AU>}

\section{$<\mathrm{H}_{1}>\mathrm{ABSTRACT}</ \mathrm{H}_{1}>$}

$<$ ABSTRACT>An extension of gentrification, jiaoyufication-urban change driven by a desire for high-quality education-is not only displacing previous lower-class residents, but also replacing earlier jiaoyufiers with newcomers, turning formerly blue-collar neighbourhoods into white-collar ones. New middle-class communities are emerging as spatially limited school catchment zones attract social groups who occupy these spaces in an attempt to facilitate social mobility or consolidate social status, causing tension between them. Consequently, jiaoyufication has narrowed down opportunities for intergenerational social mobility and exacerbated social polarization, gradually replacing traditional social hierarchies with intergenerational neoliberal stratification. </ABSTRACT>

\section{$<\mathrm{H}_{1}>$ Introduction $\left.</ \mathrm{H}_{1}\right\rangle$}

Unprecedented rapid neoliberal urbanization in China during the reform era has stimulated a series of substantive and complicated social, economic and spatial transitions. Among them, a form of gentrification-what Smith (2002: 427) calls a 'sporadic, quaint and local anomaly'-has taken on unique characteristics within a particular strategy of capitalist production-based, revanchist urbanization. Jiaoyufication, from the Chinese word jiaoyu, translated as 'education' in English, reflects a newly constructed space in Chinese cities (see Wu et al., 2016; 2017 for a more detailed explanation). Jiaoyu refers mainly to primary and secondary schools in this article. More specifically, jiaoyufication centres upon the acquisition of apartments within the urban catchment areas of prestigious primary and secondary schools. When jiaoyufiers, who demand high-quality educational resources move into these inner-city areas, they not only displace the lower class (Newman and Wyly, 2006; Forrest, 2015) but also replace the former jiaoyufiers (Wu et al., 2017). This inner-city gentrification transition process has been primarily a market-driven force in contrast to state-dominated urban redevelopment through a process of formalization (WU, 2016). Consequently, new middle-class communities are emerging through the (re)production of social space (Lefebvre, [1974] 1991). As with conventional processes of gentrification, these

This is the author manuscript accepted for publication and has undergone full peer review but has not been through the copyediting, typesetting, pagination and proofreading process, which may lead to differences between this version and the Version of Record. Please cite this article as doi: 10.1111/1468-2427.12568

This article is protected by copyright. All rights reserved. 
spaces foster middle-class attitudes and identities through jiaoyufication-based cultural (re)production (Willis, 1981; Wu et al., 2016). As an extension of gentrification, the process of jiaoyufication is characterized by middle-class strategies to claim educational advantages (Wu et al., 2014). As an education-led, social-capital-based form of gentrification distinct from the property-led gentrification that has been used as an urban strategy for Chinese neoliberal urbanization (Wu, 2016), jiaoyufication introduces educational/social capital into the kind of economy-based gentrification process theorized by Smith (Wu et al., 2017).

In the Chinese context of jiaoyufication, there has been an evolving strategic 'battle' over space as part of the process of middle-class remaking. Social tension suffused the social-spatial relationships between classes as they fought for high-quality educational resources during the initial stages of China's urban restructuring. This has subsequently led to further contestation around social consolidation and class mobility. On the one hand, in order to be close to the upper class and maintain their status (Wilson and Schulz, 1978), jiaoyufiers, as members of the urban middle class, seek to demonstrate their superiority through cultural reproduction and by distinguishing themselves from other social classes. On the other hand, members of the lower-middle class are eager to challenge the existent social hierarchy and penetrate the higher echelons of the middle class. In this sense, the lower-middle class is a 'sandwich' stratum that seeks to maintain social position while looking for ways to attain higher status. In a reformed, (post)industrialized China, the limited high-quality educational resources offered by the most prestigious schools have become a pivotal focus in the battle for increasing social mobility and class consolidation for middle and lower social groups (Breen and Karlson, 2014; Magnani and Zhu, 2015).

The battle over cultural reproduction has been further intensified by jiaoyufication in a geographical sense, extending privilege-based socio-economic competition to particular spaces (Lefebvre, [1974] 1991). According to Wu et al. (2016), jiaoyufication refers to an interweaving process in which lower-class residents are displaced by middle-class jiaoyufiers, and, in the resultant urban enclaves, these pioneers are then replaced by peer successors. Jiaoyufication is thus a transitional process from gentrification to residential segregation that is not subject to reversal. Both high-quality educational resources and residential properties within jiaoyufication zones are limited. Accordingly, middle-class anxiety about the loss of social status (Ehrenreich, 1990) generates an intensified battle over limited educational and scarce spatial resources. This results in an emergent form of spatial distinction that signifies a change from differentiation based on a privileged education to differentiation that is territorially based (Soja, 1996; McDowell et al., 2006; Wu et al., 2015), exacerbating social segregation.

These tensions over social and spatial (re)production have amplified intense competition between the urban new rich ( $\mathrm{Li}, 2003$; Wu et al., 2014), the traditional middle class and upper fractions of the blue-collar class (Wilson and Schulz, 1978). Among these contenders, the urban new rich who have emerged in the reform era are the most eager to become assimilated into the middle or upper strata. This distinctive class, who possessed 
less cultural capital in the pre-reform era, have benefited from a great increase in economic capital in the era of market reform.

In further exploring these forms of class remaking and contestation, the remainder of this article consists of four sections. The first reviews the literature on jiaoyufication and draws implications about China's urban developments. The second discusses how in-depth interviews have been utilized to illustrate how class struggle is embedded in the practice of jiaoyufication. By revisiting the existing literature and evaluating empirical findings, the third section elaborates on how limited access to scarce educational resources provokes strategies to seek social mobility and status consolidation that intensify class relations. The final section elucidates the implications of revealing a new form of social-spatial segregation within a revanchist urbanism in China.

\section{$<\mathrm{H}_{1}>$ Understanding jiaoyufication within the context of space and cultural (re)production $\left\langle/ \mathrm{H}_{1}\right\rangle$ \\ Initially, conceptions of gentrification accounted for the process through which} older residential buildings in inner-city communities were rehabilitated and working-class occupants displaced by richer middle-class incomers (Hamnett, 1991). However, as Smith (1996) contends, gentrification more broadly refers to the (middle-)class remaking of urban (and rural) spaces, a process which mutates according to the spatio-temporal contexts in which it occurs. Subsequently, research has increasingly reflected the acceleration and diversification of urban restructuring, as well as the increasing size and diversity of middle classes around the world. Accordingly, an understanding of what constitutes gentrification has expanded to encompass broader processes through which former residents are displaced, class conversion within neighbourhoods occurs, properties are upgraded, and rent gaps are exploited for profit making purposes (Lees et al., 2008).

A diverse range of educational and cultural theories have endeavoured to explicate these urban transformations of class and space. Drawing on Bourdieu's ([1979] 1984) theories of distinction, Bridge (2001) points out that gentrification exemplifies strategies of social and cultural reproduction through the performance of a middle-class habitus in redeveloped areas of the inner city. Home-making, design, cultural and consumptionoriented practices reproduce both place and class. These gentrified communities thereby delineate and reproduce daily urban practices that undergird structuralized rules and resources (Giddens, 1984). They can be considered as forms of cultural (re)production that contribute to social reproduction and act to sanctify these communities as sites of middleclass remaking that also reproduce social space (Lefebvre, [1974] 1991; Smith, 1996).

In China, children can enrol at a nearby public school to receive a nine-year compulsory education (from primary to junior secondary school), based on the hukou registration that is linked with their parents' property. This institution was enacted to ensure fairness in education. However, the quality of educational resources has been spatially differentiated between regions (for instance, between rural and urban, or coastal and inland) and locations (city centre and urban fringe) (Hannum and Wang, 2006). 
Subsequently, students have been allowed to enrol in a better school in another district by paying a school choice fee. This policy has stimulated the formation of Xuequ buildings (see Figure 1), which are located within the catchment area of key schools. This process is called jiaoyufication (Wu et al., 2014; Wu et al., 2015).

Since the early 2000s, as a recent extension of education-led gentrification has manifested itself in Chinese inner cities, jiaoyufication has revealed the colonization of school catchment areas by the professional and managerial classes. Through such strategies, middle-class families try to achieve upward mobility and cultural (re)production by securing the limited housing located in key school catchment areas (edu-apartments). This represents two threads: space making and class making.

The first thread is that jiaoyufication has generated and enhanced residential segregation through distinguishing key edu-apartment communities from other neighbourhoods (Rowe, 2014; Wu et al., 2015). During the initial stages of jiaoyufication, this inevitably displaced lower-class inhabitants (Rose, 2013), primarily the blue-collar workers of former state-owned and collective-owner enterprises (SOEs and COEs respectively) in the planned economy era (Wu and Webster, 2010). Accordingly, the coexistence of different social groups within the catchments of prestigious schools has gradually been replaced by internal middle-class homogeneity (McDowell et al., 2006). Because the initial displacement of lower-class residents in these edu-apartments has been taken over by the replacement of jiaoyufiers with newcomers of a similar class, jiaoyufication demonstrates the unique characteristics of a reverse neighbourhood filter, contrasting with situations in which upwardly mobile residents depart an inner-city neighbourhood and leave poorer neighbours behind, thereby degrading the status and quality of the area (Hedin et al., 2012). Instead, segregation is produced through the prevention of lower-class people from returning to the areas (see Figure 1). For instance, Wu et al. (2016) reveal that, through jiaoyufication processes in the inner city of Nanjing, wealthy jiaoyufied families displaced the original lower-class families in key schools' catchment areas and acted as the gatekeepers of the housing market in resisting lowerclass penetration, consequently reinforcing residential segregation.

\section{$<$ INSERT FIGURE 1 NEAR HERE>}

The second thread is that jiaoyufication gives rise to social reproduction through cultural reproduction, resulting in class remaking (Figure 1). Through daily practices and routines of cultural production emerging from particular expressions of middle-class habitus (Bourdieu, [1979] 1984; [1982] 1991), an ongoing process of class making unfolds. Sites such as coffee shops and tea bars serve as venues for new and traditional consumption practices respectively, highlighting the distinctive differences that such practices might express. The social consequences of these endeavours to reproduce cultural capital may result in the consolidation of the intergenerational social status of middle-class families (Robson and Butler, 2001). But they may also provoke 
intergenerational or intra-generational upward social mobility that is pursued by lowerclass and newly rich families with lower social and cultural capital than existing jiaoyufiers (Brown et al., 2013). Accordingly, jiaoyufication is more concerned with social class reproduction through territory-based cultural production within the catchment area of 'good' schools. By contrast, other sociological studies in China focus solely on the reproduction of middle-class identity through intergenerational cultural reproduction or everyday practices within the social hemisphere (Tomba, 2004). Consequently, the territory-based displacement wrought by jiaoyufication stirs class tension more profoundly than other middle-class remaking processes, since, for example, the rights of the lower classes to receive a good education have been removed as middle-class families have extensively competed with each other for limited educational opportunities.

Because of an ongoing battle over scarce educational resources and limited residential space, inter-individual and inter-group tensions are inevitable. These strategies for middle-class remaking further enhance and intensify the restless social conflict that is emerging in the transition era of urban China (Chan, 1996; Nee, 1996; Bian, 2002; Bian et al., 2005; Logan, 2008). Indeed, there are at least three social groups involved in the battle for edu-apartments-the new rich, professionals and intellectuals, and bureaucrats-who possess different levels of power, authority and fortune.

The new rich accumulated large fortunes during market transition (Goodman and Zang, 2008). However, they tend to lack the manners and language use that express the cultural capital of middle and upper-class people and are applied by the latter to secure educational advantages for themselves and their children (Nash, 1990; Bourdieu, [1982] 1991). In popular culture, they are frequently labelled as nouveau-riche parvenus who behave improperly even though they may be dressed in expensive clothes and drive luxury cars (Pinches, 1999). Such stereotyping has recently extended to internet slang through which they are identified as tuhao (土豪) or BMW (wo)man (宝 $\square$ 男（女)amongst other epithets. The former term connotes those whose new wealth is accompanied by rude and impolite behaviour, while the latter refers to their ostentatious display of wealth through car ownership. Even if the new rich own substantial economic capital, however, they may not be regarded as orthodox members of the middle or upper class. As a result, they have strong motives to seek a good education for their children so that they may be granted the cultural reproduction for which they are eager and become assimilated into mainstream middle-class society (Lan, 2014; Baltzell, 2011). Since these new rich tend to possess more financial capital than their peers bidding for the scarce edu-apartments within the key school catchments, they aggravate the tense relations generated by the battle over core educational resources in the urban housing market.

While professionals or intellectuals are rich in cultural capital (Gramsci, [1966] 2005), they own less economic capital and thus rely more on cultural reproduction for class consolidation and increased social mobility (Wilson and Schulz, 1978; Power et al., 2003; Baltzell, 2011). Meanwhile, middle-ranking bureaucrats are normally endowed with more political capital through their sophisticated use of institutional arrangements than other 
social groups in the battle for edu-apartments, as well as having greater access to highquality educational resources.

Undoubtedly, jiaoyufication has contributed to cultural-reproduction-based class restructuring in urban China through educational accessibility. This may unlock the pathdependence of social-hierarchy-based social segregation, and add to or gradually replace it with a territory-based segregation based on middle-class remaking through jiaoyufied space production. The methods and case studies in the following sections aim to understand the social interactions shaping the pattern of jiaoyufication using quantitative and qualitative means.

\section{$<\mathrm{H}_{1}>$ Methods and case studies $</ \mathrm{H}_{1}>$}

Although Nanjing has been downgraded to the status of a regional city since 1949, it remains a national centre for science, technology and education. It not only has 54 universities, over 800,000 college students and 2.61 million residents with college degrees or above (31.89\% of total registered population: NSB, 2014), but also is reputed to be one of the most advanced cities for pre-higher (primary and secondary) education in all China. As such, Nanjing is an ideal site to study jiaoyufication as part of China's current culture-driven urban social-spatial transition. Figure 2 shows the location of our study area.

\section{$<$ INSERT FIGURE 2 NEAR HERE>}

This study makes use of a hybrid research approach that mixes qualitative and quantitative methods. On the one hand, a wide range of materials were drawn from interviews and participant observation carried out between 2012 and 2015 . Extensive interviews with 37 people were conducted with the following participants: (1) six teachers with different roles, from school principal to general tutor; $(2)$ two officials in municipal and district educational bureaus; (3) ten parents with different occupations and professions, whose children had entered supposedly key schools or had planned to do so; (4) seven estate agents with different positions (from deputy general manager to low-level manager) in different agencies (from real estate companies in a national chain to local family-run companies); (5) two social researchers in higher educational institutions; and (6) ten property owners with edu-apartments and non-edu-apartments. These in-depth interviews were conducted in edu-apartment zones to reveal the process of education-driven space (re)production. The study also explored the potential tensions in the real estate market and residential zones among different social groups, who practised educational strategies of class production, both consciously and unconsciously (Bourdieu, [1979] 1984), and subsequently occupied edu-apartments around key schools and consolidated the classremaking trajectory for which they aimed (Filion, 1991; Waters and Brooks, 2010).

In addition, a web-based stratified sampling questionnaire survey (Loehlin, 1998; McAfee and Brynjolfsson, 2012) was conducted between 2014 and 2015 that involved 1, 233 college graduates aged 18-35 (see details in the Appendix), followed by occasional face-to- 
face interviews with 15 participants subsequently selected from among them. This data was then used to develop two structural equation models using the statistics analysis software package (AMOS v22-Analysis of Moment Structures $<\mathrm{FN}_{1}>$ ), which aims to reveal the causal and path relationships between pre-higher education, educational attainment and living conditions. Structural equation modelling (SEM), as a relatively new method of modelling and a specific type of econometric analysis, mixes confirmatory factor analysis, path analysis and regression analysis, and so can explain the structural relationships between multiple dependent and independent variables. The variables are split into two categories: measurable or latent (not observable) variables, and exogenous or endogenous variables. A latent variable or construct (e.g. compulsory education) is usually defined and quantified by measurable or observable variables (e.g. primary school). In contrast to endogenous variables, an exogenous variable is not affected by models but determined by factors outside of the models.

Compared with the ordinary least-square (OLS) regression model, the SEM model, estimated by using the maximum likelihood method, is less sensitive to multicollinearity, the assumption of normal distribution and measurement error. The popular statistic chisquare is sensitive to sample size. Consequently, several other indices are frequently used for judging goodness-of-fit from varied perspectives (e.g. Goodness of Fit Index (GFI), Comparative Fit Index (CFI), Normed Fit Index (NFI), Incremental Fit Index (IFI), Parsimonious Goodness of Fit Index (PGFI), and Parsimonious Normed Fit Index (PNFI)).

The SEM method usually outputs two types of model: measurement and structural models. A measurement model shows the relationships between a latent construct and its indicators. A structural model imputes causal dependencies (relationships) between latent constructs. A typical output of an SEM model is a path diagram, the structural model part. In the diagram, ovals indicate latent constructs and rectangles observable variables. The true circle is the error term and its value indicates how error influences an observed variable. Arrows with single heads show path regression indicating the strength of the relationship and arrows with heads at both ends show covariance. The path diagram can be used to analyse various effects between latent constructs. SEM makes a distinction between the direct, indirect and total effect that one latent construct has on another. Direct effect is the link going directly from one variable to another. Indirect effect occurs between two variables mediated by one or more intervening variables. Total effect is the sum of direct and indirect effects. These will provide more accurate statistics in estimating causal relationships. Another strength of SEM is that nonparametric SEM permits the estimation of the three effects without making any commitment to the form of the equations or to the distribution of the error terms. This has made the SEM method particularly useful for modelling social interactions in many disciplines (see examples in Ramkissoon et al., 2013 and Deutsch et al., 2013).

In this study, two SEM models, focusing on higher education and living conditions separately, are developed using the web-surveyed data sets described above. These models aim to analyse the causal relationships between the specific social factors, which 
contribute to the decision behaviour of jiaoyuficated families and the social impacts of jiaoyufication. There are eight hypotheses assumed for understanding the social process of jiaoyufication: $\mathrm{H}_{1}-\mathrm{H}_{4}$ for the path to living conditions and $\mathrm{H}_{5}-\mathrm{H} 8$ for the path to higher education, which have been represented into Figure 3.

In Figure 3, on the right, higher education is related to the three social factors: senior high school, compulsory education and family background; while, on the left, living conditions are related to the three social factors: higher education, compulsory education and senior high school. These models will test the eight hypotheses (hypotheses $\mathrm{H}_{1}-\mathrm{H}_{4}$ on the left, and $\mathrm{H}_{5}-\mathrm{H} 8$ on the right) and evaluate the paths, which will be discussed in greater detail below.

$<$ INSERT FIGURE 3 NEAR HERE>

\section{$<\mathrm{H}_{1}>$ The socio-spatial landscape of jiaoyufication in Nanjing $</ \mathrm{H}_{1}>$}

$<\mathrm{H}_{2}>$ Jiaoyufied space production process $</ \mathrm{H}_{2}>$

The production of space in a jiaoyufied field involves not only institutional arrangements but also the significance of differential political entitlement to jiaoyufication, implying an uneven geographical development in the production of difference at various spatial scales (Harvey, 2005). This reflects three stages of resident relocation-based urban transition. The first takes the form of traditional gentrification (Hammelt, 1991; Ley, 2003) whereby the jiaoyufiers displace blue-collar workers through the real estate market and subsequently transform their neighbourhoods by populating them with a new generation of middle-class inhabitants (Bridge, 2001; Ley, 2003). For the lower-class residents who accepted financial offers from these rich jiaoyufiers, this seemed like a 'good deal', and they were 'happily' relocated. However, in agreeing to this practice, lower-class families had to sacrifice opportunities for intergenerational cultural reproduction through education. In fulfilling their immediate needs for accommodation, they fell into the trap of social unsustainability, since these properties had been the only possession they had ever owned, apart from their labour. When one interviewee, a retired worker, was asked about these apparent disadvantages, he replied with some disappointment, after a long silence:

$<$ EXTRACT>I ought to have bought a bigger space for the whole family ... oughtn't I? ... they [his grandchildren] are worker's children, maybe not good at school.</EXTRACT>

This story echoes Willis's (1977) assertion that the social reproduction of the working class exceeds divergences in fortune and power, as exemplified here, where hopes for achieving social mobility through schooling are thwarted.

In the second stage, and as a consequence of the process by which jiaoyufiers bought the residences of blue-collar residents, the edu-apartment zones entered a period of hybrid transition. During this period, most of the remaining lower-class inhabitants were 
progressively displaced by further jiaoyufiers, in addition to which earlier jiaoyufiers whose children had come to the end of their secondary education sold their properties and were replaced by newcomers of the same social status. An original inhabitant described the displacement process:

$<$ EXTRACT $>$ We were workers in a boiler factory [that subsequently went bankrupt] before the reforms. We and our original neighbours [and co-workers] were all employed in the same danwei; they have nearly all moved out. As for our new neighbours, we hardly know them. They bought the flats here for schooling. $</$ EXTRACT $>$

The third stage was typified by the departure of the remainder of the lower-class families as the process of gentrification fostered new forms of urban alienation, and as jiaoyufication zones became a type of middle-class urban enclave (Breitung, 2012; Wu et al., 2015) in which only a few blue-collar residents lingered, isolated from residents of a similar class. As an elderly couple, formerly blue-collar workers, remarked:

$<$ EXTRACT>Our original neighbours [their co-workers in the same danwei] have nearly all moved out ... We know little about our new neighbours.</EXTRACT>

$<\mathrm{H}_{2}>$ Jiaoyufication-based cultural production process $</ \mathrm{H}_{2}>$

Jiaoyufication demonstrates a distinctive process of stratification between jiaoyufiers and the lower classes that is organized around pre-higher education and creates different modes of distributing cultural capital and reinforcing cultural class reproduction. Bourdieu and Passeron ([1970] 1990) argue that social classes possess different cultural capital capacity, and contend that the education system has a particularly critical role in the (re)production of cultural capital. Accordingly, differential accessibility to stratified education resources delineates the pathways of cultural production and, consequently, changes the trajectory of social reproduction in class remaking (Sullivan, 2001; Andersen and Hansen, 2012). The web-survey conducted in Nanjing underlines how this educational stratification powerfully impacts cultural production and social class formation by differentiating standards of educational attainment between different social groups, thus echoing Nash's (1990: 432) comments that 'the school has become the most important agency for the reproduction of almost all social classes'. Grounding these abstract perspectives, an interviewee displayed a passion for using the edu-apartment to ensure his child could study in a good school. Here, a newly rich middle-class father emphasizes how education can demonstrate his recently acquired status despite the scorn of older middleclass groups:

$<$ EXTRACT>I know our [family's] disadvantages in culture, although we have more money [than middle-class people, especially, intellectuals] ... but my kids ought to 
learn more to be respected [by other middle-class fractions] ... I think we [rich but less educated families] deserved this [the purchase of an expansive eduapartment].</EXTRACT>

Certainly, jiaoyufication-based cultural production dynamics can be deconstructed to identify two successive paths or impacts of cultural stratification through the structural models in Figure 4. The NFI/CFI statistics calculated from models A and B are 0.970/0.98 and $0.977 / 0.997$ respectively, which indicates their statistical significance.

In Figure 4 (model A), there are three latent constructs (higher education, compulsory education and family background) and nine observed variables. The first latent construct, compulsory education, is explained by three observed variables: primary school, junior high school and senior high school. The second latent construct (exogenous variable), family background, is explained by four measurable variables: hukou of parents, father's educational background, mother's educational background and occupation of parents. The third latent construct, higher education, is explained by two observed variables: degree and college.

In Figure 4 (model B), there are also three latent constructs ( $r 1-3$ ) (higher education, compulsory education and living conditions) and eight observed variables. The latent construct, living conditions, is explained by three observed variables: housing, income and occupation. The other two latent constructs are explained by the same set of variables as modelled in Figure 4. The results of the models, i.e. coefficients, will be interpreted in the following sections.

\section{$<$ INSERT FIGURE 4 NEAR HERE>}

$<\mathrm{H}_{2}>$ The impact of stratification in pre-higher education upon higher education attainment differentiation $\left\langle/ \mathrm{H}_{2}>\right.$

The structural model of education in Figure 4 (model A) demonstrates that family status determines or influences educational stratification from primary education to higher education. Family background, as identified via the variables of the parents' hukou, educational background and occupation, clearly has a significantly positive relationship with educational progress in the structural mode, in which the standardized path regression coefficient was 0.46 .

However, there is less direct impact of family status on higher educational segregation at a later stage, evidenced by the positive path coefficients, which have dropped from 0.46 (on pre-higher education) down to 0.22 (on higher education stratification). Attainment here seems to rely more on individual ability and disposition to study rather than family background. Nevertheless, the data reveal that attendance at particular primary and junior secondary schools (indicated by the construct of Compulsory Education) has positive impacts on the senior secondary school attended (indicated by the construct of Senior High School), as shown in Figure 4, model A (where the path coefficient is 0.52 ), which in turn has an important positive impact on higher education pathways 
(where the path coefficient is 0.36 ). In fact, the pathway of cultural (re)production by which the rich can buy both access to good pre-higher education and indirect access to higher education for their children is much more effective than cultural acquisition through directly 'investing' in their higher education, since strict university enrolment policies restrict such access. Thus, the pathway reveals the reasons for the battle over limited jiaoyufication housing among newly rich and conventional middle-class families.

Interestingly, similar evidence has been found by analysing the school registration system data of Arizona, USA, in 2015, and field survey and in-depth interviews with realtors, parents and students in Vancouver, Canada, in 2016, that rich locals or international immigrant families geographically concentrate in the catchment areas of 'good' schools more than lower-income residents, who register their children in randomly allocated schools of lower reputation. Future research will ascertain whether education-led, territory-based jiaoyufication is an emergent global form of gentrification.

$<\mathrm{H}_{2}>$ Higher education-led social stratification $</ \mathrm{H}_{2}>$

Certainly, in contrast to primary education, which has little impact on educational attainment, higher education stratification significantly influences the socio-economic status of the younger generation (Sewell and Hauser, 1972). The structural model in Figure 4 (model B) shows that better attainment in higher education leads to choice of good residential location and occupation of expensive accommodation in later life. Higher education has a very high positive impact on living conditions as the path coefficient from the construct of higher education to that of living conditions is very high (0.74) which, in turn, has a positive impact on occupation, income and housing-as indicated by their coefficients: $0.19,0.60$ and 0.48 respectively (Figure 4 , model B). Once families have purchased an edu-apartment, they tend to ensure their new generations' upward social mobility through educational attainment.

\section{$<\mathrm{H}_{1}>$ Social-spatial meaning and the consequence of jiaoyufication $</ \mathrm{H}_{1}>$}

$<\mathrm{H}_{2}>$ Class remaking through the production of jiaoyufied space $\left.<\mathrm{H}_{2}\right\rangle$

Jiaoyufication reveals that space has a pivotal role in shaping social reproduction (Giddens, 1984). The processes by which jiaoyufied space is (re)produced encourage the middle class to occupy it as a setting for social consolidation or social mobility. Accordingly, this jiaoyufied space is distinguished as a site of middle-class remaking from other spaces, such as those within the catchment areas of non-key schools. Indeed, the institutional arrangements of educational zoning have lasted for nearly three decades since 1986, when the Compulsory Education Law was issued, continuously reproducing the conditions for jiaoyufiers' cultural and social (re)production. Since such institutional arrangements change very slowly, tensions between middle-class families over accessibility to schools intensify, provoking those who are unsuccessful in securing edu-apartments to argue with the education bureau, petition city governments or, as a last resort, to organize public 
demonstrations. Nevertheless, as Lefebvre ([1974] 1991) emphasizes, space is a concrete abstraction of historically specific materials, concepts and daily practices. Accordingly, no matter how the inhabitants of jiaoyufication zones respond to the adjustment of educational policies in quotidian practice, they occur within a space that has been (re)shaped by institutional arrangements. That is to say, the concrete quotidian practices of jiaoyufiers, such as purchasing and selling edu-apartments, schooling, and socializing with neighbours have emerged within the abstract political settings of (middle) class formation and control of class mobility.

Jiaoyufied space and its (re)production anchor the geographical differentiation of educational arrangements through a complicated yet stabilizing and enduring path of regionalization (Giddens, 1984) that involves daily practices of cultural and social (re)production (Willis, 1981). In reality, jiaoyufication zoning at different stages is a spatial consequence of social contention between different social groups for limited high-quality educational resources. An official who owned a danwei department of a provincial educational apartment within a key school catchment area smirked:

$<$ EXTRACT>Our neighbourhood was outside the catchment area of Lixue Primary School at first [see Figure 1], but [for emphasis] how could they [the municipal education bureau in charge of zoning the catchment areas in each city] make such an oversight? ... We [the original residents] are employees of the provincial education department! [the municipal education bureau is under its supervision] ... Later, we [the neighbourhood] were [situated within the catchment of Lixue Primary School] ... Sure, my work unit [provincial educational department] of course takes advantage of it [the zoning policy] to provide benefits for its employees. $</ E X T R A C T>$

On the other hand, an owner of a non-edu-apartment next to an edu-apartment zone criticized these arrangements:

$<$ EXTRACT $>$ [The zoning policy] is irrational ... inclined to favour the rich people and resource-controlling danwei ... they [the resource-controlling danwei and educational bureau] regulated it [educational zoning] but ... is it right that the poor and work units cannot control these resources and only deserve a poor-quality school?</EXTRACT>

In this context of middle-class formation, a jiaoyufied habitus contributes to the disparities between jiaoyufied places and non-jiaoyufication zones and consequently perpetuates cultural (re)production. That is to say, these forms of habitus have been embedded within the structuralized differentiation of educational resources by institutional arrangements and market forces from global to individual scales, and from national to local community contexts (Richardson and Jensen, 2003). The Chinese Communist Party's practice of developing an elite education tradition since the 1950s, the emergence of neoliberal educational reform on a national scale in the 1980s (Chan and Mok, 2001; Mok et 
al., 2009), and policies of introducing school fees (including the 'Temporary Schooling Fee', 'Choice Fee' or 'Increasing Enrolment Fee') $<$ FN2> have encouraged real estate agencies to transform the edu-apartment market since the early 2000 s.

School fees demonstrate a close practical and theoretical relation to jiaoyufication, since paying for high-quality education reflects how economic capital is superior to social/cultural capital acquisition, as articulated by Bourdieu ([1983] 2011). Undeniably, jiaoyufication clashes with the mooted association between neoliberal educational reform and the requirements for egalitarianism in the post-reform practice of China. However, jiaoyufication does temporarily promote a varied social mix, although it will likely cause greater segregation in the long run. Consequently, we call for further research into urban strategies that aim to provide equal education rights among a wide range of social classes, of the kind that the US has endeavoured to achieve with regard to college admission among a variety of races.

Jiaoyufied space has been manipulated to serve political strategies that govern educational capital distribution between social groups and classes. With reference to this, an official of the educational bureau commented:

$<$ EXTRACT>Since we lack enough [good educational resources] to distribute, [we] have to settle upon a solution to zoning edu-apartments ... based on tradition ... but it [the zoning policy] has been inevitably impacted by [powerful or resource-controlling] work units .... A person or danwei in a favourable position gains special advantages. $</$ EXTRACT $>$

Accordingly, by manipulating the governance of educational capital distribution, jiaoyufied space has become an expression of the state's will, reflecting the interests of a dominant social elite group and resonating with the normative cultural desires of mainstream society. Consequently, it has inadvertently created a path-dependence for middle-class social reproduction through cultural (re)production. Nevertheless, within the field of jiaoyufication, each individual jiaoyufier develops a habitus that combines with a set of collective dispositions (Bourdieu and Passeron, [1970] 1990; Bridge, 2001) in the process of class remaking. For instance, schoolchildren not only develop enhanced confidence and achieve better educational attainments than their peers in common schools, but also belong to more prestigious social networks, as revealed in an interview with a parent:

$<$ EXTRACT>It [classmate relationship in key schools] is also an asset when they grow up ... after all, guanxi [personal relations] is very important to Chinese society ... [they are] children of government officials, professors, managers and officers in the army.</EXTRACT>

In addition to the social networks forged between school children, their parents-from middle-class elites with varied social backgrounds-also create high-level social networks. 
Both forms of network will undoubtedly help to upgrade the social and occupational mobility of these students.

Furthermore, the ruling classes have manipulated the jiaoyufied zones in a sophisticated way to divert and weaken resistance in the form of bottom-up public criticism, a form of cultural violence fatalistically referred to by a parent residing in a nonedu-apartment:

$<$ EXTRACT>My family can't afford such an edu-apartment ... and I do not possess the necessary social relationships [personal connections] ... and so I have to send [my child] to the Primary School on Hankou Road [a non-key school neighbouring the best key schools in Nanjing] ... I can only hope that he studies hard to go to a good secondary school with a good grade.</EXTRACT>

$<\mathrm{H}_{2}>$ Narrowing the traditional path of bottom-up social mobility $</ \mathrm{H}_{2}>$

Bourdieu ([1983] 2011) asserts that cultural capital may be conditionally converted into economic capital. There has been a paradoxical relationship between education/cultural capital acquisition and the social status expected in jiaoyufication for the following reasons. In the structural model shown in Figure 4, family background, as a latent construct, is indicated by four observed variables, among which the educational background (e.g. years of study) of parents is conceived of as cultural capital, while the hukou of the parents and their occupations are expressions of social status. Here, we can elucidate these issues by referring to the models.

The structural model demonstrates a positive causal relationship between the latent construct of family background and cultural capital and social status (Figure 4, model A). For instance, the standardized factor loading of cultural capital is higher than that of social status ( 0.84 and 0.77 for cultural capital in comparison to 0.53 and 0.46 for social status). This means that cultural capital makes more contributions to family background than social status. The effects we are studying could be created either by a direct route (i.e. through family background) or an indirect one (following a clear pathway from family background to compulsory education, to senior high school and eventually to higher education). Consequently, class formation, manifested as living conditions (a latent construct indicated by the three observed variables: housing price, income, and the prestige of occupation in Figure 4, model B), was strongly influenced by higher education and further affected by parents' cultural capital and social status, on the one hand, and their family background, on the other.

However, since the pivotal function of jiaoyufication has been to achieve access to high-quality educational resources (from kindergarten to Grade 9) through the purchase of an edu-apartment, it is clear that the real estate market is taking advantage of the demand for edu-apartments by inflating prices to a far higher level than before. Real estate companies compete to develop new residential buildings within the catchment areas of well-known key schools and sell them at a much higher price than those in neighbouring 
areas. As an employee of a real estate agency frankly acknowledged, 'we live on the commission from housing transactions ... the higher the price is, the more commission fee we charge'. Such a strategy requires that jiaoyufiers attain a higher level of economic capacity than they previously enjoyed.

In fact, there are three pathways to inflate the housing price in jiaoyufication zones (Wu et al., 2017). The most significant strategy adopted by owners in some neighbourhoods is to keep the property and wait for potential regeneration, so that the new-built eduapartment provides owners, real estate agents and developers with a much higher reward. Yet, while average family income increased by $25 \%$ per year, from 1995 to 2014 the cost of an edu-apartment increased by $39 \%$ per year according to our survey, further restricting traditional opportunities for bottom-up social mobility. While the acquisition of cultural capital might initially be a powerful asset in achieving upward social mobility, at this later stage of the jiaoyufication process, economic rather than already existing cultural capital is required in the remaking of middle-class identity. Accordingly, the path of jiaoyufication has been narrowed down by the restrictions imposed by the market, excluding less affluent intellectual families from conventional middle strata, and making new middle classes who 'buy' cultural capital.

This tendency suppresses intra-generational social mobility to some degree and exacerbates intergenerational mobility by narrowing the channels for the bottom-up social mobility that has been regarded as a traditional solution to releasing class tensions. Traditionally, the lower class could achieve an intergeneration-based upward social mobility through educational attainment (Waters et al., 2010). As Bourdieu ([1979] 1984) mentions, the logic of transformation between different forms of capital, for instance via prestige, wealth and power, foregrounds how economic capital is superior to cultural capital. Therefore, when the urban new rich are accepted by mainstream society through a cultural reproduction perpetrated via the narrowed path of jiaoyufication, it significantly transforms the social class structure from that characterized by a Weberian trio of wealth, power and authority to a neoliberal structure in which wealth and power predominate, with a consequent increase in social polarization and spatial segregation.

$<\mathrm{H}_{2}>$ Beyond territorial tension: neoliberal social reproduction? $</ \mathrm{H}_{2}>$

Jiaoyufication is undoubtedly based on territorial competition over edu-apartments within the catchment areas of key schools; however, the geographical tension among social groups inevitably devolves into a social struggle that exceeds space. As an outcome of urban educational resource distribution, jiaoyufication emerged with the neoliberal marketization of urban education in the late 1990 (Mok et al., 2009), as scarce educational resources came to be regarded as a form of capitalized public goods that exemplified the motto of small governance and big market in Deng Xiaoping's neoliberal regime (Wong, 2004; Harvey, 2005). Since then, the rich have been able to consolidate their social status by competitively bidding for the edu-apartments with access to key schools. This strategy not only curtails the tradition of meritocratic education and consolidates social hierarchy, 
but also expands geographical unevenness on an urban scale by enlarging the rent gap through capitalizing institutional resources, further segregating the poor and the rich (Wu et al., 2017). The conflict involved in the process of jiaoyufication exceeds the territorial competition depicted from a conventional urban social ecology perspective in, the following two ways.

First, jiaoyufication is a hybrid phenomenon of gentrification and urban educational segregation. Nevertheless, it also expresses the reproduction of middle-class habitus through cultural and social reproduction (Bourdieu, [1979] 1984). As mentioned above, due to the creative-destructive strategy of jiaoyufication, the traditional Weberian intra/intergeneration-based stratified society with three structures shaped by wealth, power and prestige (Waters et al., 2010), have been trimmed down into an intergenerationbased stratified society with dual structures, as wealth and power gradually come to dominate the social stratification of post-Mao China. Consequently, a distinctly neoliberalist social hierarchy has been enhanced and the ruling class's social control reinforced by the cultural (re)production generated by jiaoyufication, through which the new rich of the reform era are gradually absorbed into the dominant classes.

Second, jiaoyufication involves a particular Chinese revanchist urbanism. Revanchist urbanism initially refers to how gentrification constitutes a switch toward the reinvestment of economic capital and regeneration of inner-city neighbourhoods in contrast to previous processes of suburbanization in the Western city (Smith, 1996). In China, this has been combined with a post-Maoist counterattack by the rich who had been exiled from the social mainstream by Maoist socialist policies since 1955 (Liu and Wang, 2006).

In sum, the jiaoyufication process reflects a social-spatial transformation that is an integral part of the trajectory of neoliberal reform in the Chinese city. It is undeniable that jiaoyufication is partly shaped by culture-led and education-driven processes of gentrification and territorial contestation among social classes, thus superficially seeming to be a transformation generated by a switch in cultural capital. However, more broadly, it is grounded in a globalized social transformation characterized by creative destruction as workers formerly living in danwei residences have been excluded from global socialproduction cycles and brutally expelled from the inner city (Sassen, 2014) during the economic restructuring of post-Maoist reform (Hudson et al., 2010).

\section{$<\mathrm{H}_{1}>$ Conclusions $</ \mathrm{H}_{1}>$}

Jiaoyufication has been driven by the institutional arrangements through which educational resources have been geographically redistributed (Wu et al., 2017). However, as a form of gentrification in a Chinese context, its dynamic impacts on geography extend into social struggle and conflict. With respect to its cultural and economic capital-switching, and class displacement, jiaoyufication has emerged within a geographical process of educationdriven cultural production and social reproduction. David Ley (2003) reveals how the cultural reproduction of young American professionals by renovating old inner neighbourhoods in cities plays a pivotal role in distinguishing them from other suburban 
middle-class groups. However, Chinese jiaoyufiers are far more concerned about how the educational capital of their offspring might maintain their intergenerational class identity.

Following the trajectory from individual educational production to collective social reproduction, a dialectic relationship between spatial production and class remaking has been revealed. This socio-spatial process has demonstrated that the urban new rich have been absorbed into the dominant class, while the middle class has reproduced and the inner-city urban lower class has been displaced into marginal spaces. Moreover, fierce competition between the urban new rich, the traditional middle class and the upper lower class over the limited numbers of jiaoyufied edu-apartments within the catchment areas of key schools has produced a distinctive battlefield for social mobility and consolidation.

Jiaoyufication has directly enhanced urban residential segregation and exacerbated social stratification (Zhou et al., 1998) as the urban poor in edu-apartment zones have been gradually displaced by jiaoyufiers, and key school catchments have become a sanctum of middle-class remaking and areas for the social assimilation of the new urban rich. Although both gentrifiers and jiaoyufiers have displaced blue-collar in favour of white-collar inhabitants in inner-city areas, jiaoyufiers have been less concerned about housing renovation as a means of distinguishing themselves from others, as a parent admitted when talking about the flat she owned:

$<$ EXTRACT>This, my home? ... You know, it's small and old ... It's just to get into the primary school and No. 29 Junior Middle School and that's all (Wu et al., 2017). $<$ (EXTRACT>

Unlike other new inner-city residents, jiaoyufiers are not particularly concerned by the local environment and the quality of properties since they only stay for a short period. And in contrast to Western gentrifiers, jiaoyufiers are more concerned with the acquisition of cultural capital and its transmission to their children to underpin class (re)production, and less focused upon achieving cultural differentiation solely in the educational field (Bridge, 2001). As an extended form of gentrification, jiaoyufication may thus be understood as the outcome of a distinctive form of revanchist urbanism in China.

Furthermore, jiaoyufication has narrowed the traditional path of bottom-up social mobility and enlarged social polarization in the three decades of post-Mao neoliberal reform. With the emergence of a dual structure in which only wealth and power are significant, traditionally important social groups such as scholars, farmers, artisans and merchants have become internally segregated as wealth and power are increasingly wielded by the emergent classes, while others descend into the lower classes and become increasingly marginalized. This transition not only further weakens the role of cultural/social capital in facilitating social mobility, but also changes the functions of place. For example, edu-apartments in jiaoyufied neighbourhoods have become highly mobile 'taverns', sites of elective-belonging rather than longstanding homes or homes embedded in a local place-identity. 
This research also underpins the spatial fix identified by Marxists (Harvey, 1981) as the distribution of educational resources has been transformed from being based on social hierarchy to becoming territorially configured (Wu et al., 2015). In this case, jiaoyufication has unintentionally readjusted and reshaped the spatial fix, but, more crucially, destructive cultural and social (re)production has created a tense new spatial arena for middle-class remaking in a broader context of neoliberal socio-economic restructuring.

\section{$<$ AUTHOR(S) TAG LINE (END-OF-TEXT)/AFFILIATION(S)>}

Tim Edensor, School of Science and the Environment, Manchester Metropolitan University, Oxford Road, Manchester M156BH, UK, t.edensor@mmu.ac.uk

Qiyan Wu, School of Public Policy and Administration, Xi'an Jiaotong University, Xi'an, China and Urban Studies Program, Simon Fraser University, Suite 2100, 515 W Hastings St, Vancouver, BC V6B 5K3, Canada. Qiyan_wu@sfu.ca

Jianquan Cheng, School of Science and the Environment, Manchester Metropolitan University, Oxford Road, Manchester M156BH, UK. J.Cheng@mmu.ac.uk

\section{$<\mathrm{RH} 1>$ References}

Andersen, P.L., and M.N. Hansen (2012) Class and cultural capital: the case of class inequality in educational performance. European Sociological Review 28.5, 607-21.

Baltzell, E.D. (2011) Philadelphia gentlemen: the making of a national upper class. Transaction Publishers, New Brunswick, NJ.

Bian, Y. (2002) Chinese social stratification and social mobility. Annual Review of Sociology 91-116.

Bian, Y., R. Breiger, J. Galaskiewicz and D. Davis (2005) Occupation, class, and social networks in urban China. Social Forces 83.4, 1443-68.

Bourdieu, P. ([1979] 1984) Distinction: a social critique of the judgment of taste. Harvard University Press, Cambridge, MA.

Bourdieu, P. ([1982] 1991) Language and symbolic power. Harvard University Press, Cambridge, MA.

Bourdieu, P. ([1983] 2011) The forms of capital. In I. Szeman and T. Kaposy (eds.), Cultural theory: an anthology, Wiley-Blackwell, Malden, MA.

Bourdieu, P. and J.C. Passeron ([1970] 1990) Reproduction in education, society and culture. Second edition, Sage Publications, Thousand Oaks, CA.

Breen, R. and K.B. Karlson (2014) Education and social mobility: new analytical approaches. European Sociological Review 30.1, 107-18.

Breitung, W. (2012) Enclave urbanism in China: Attitudes towards gated communities in Guangzhou. Urban Geography 3.2, 278-94.

Bridge, G. (2001) Bourdieu, rational action and the time-space strategy of gentrification, Transactions of the Institute of British Geographers 26. 2, 205-16. 
Brown, P., D. Reay and C. Vincent (2013) Education and social mobility. British Journal of Sociology of Education 34.5/6, 637-43.

Chan, D. and K. Mok (2001) Educational reforms and coping strategies under the tidal wave of marketisation: a comparative study of Hong Kong and the mainland. Comparative Education 37.1, 21-41.

Chan, K.W. (1996) Post-Mao China: a two-class urban society in the making. International Journal of Urban and Regional Research 20.1, 134-50.

Deutsch, K., S.Y. Yoon and K. Goulias (2013) Modeling travel behavior and sense of place using a structural equation model. Journal of Transport Geography, 28, 155-63.

Ehrenreich, B. (1990) Fear of falling: the inner life of the middle class. Harper Perennial, New York, NY.

Filion, P. (1991) The gentrification-social structure dialectic: a Toronto case study. International Journal of Urban and Regional Research 15.4, 553-74.

Forrest, R. (2015) Commentary: variegated gentrification? Urban Studies 53.3, 609-14.

Giddens, A. (1984) The constitution of society: outline of the theory of structuration. University of California Press, Berkeley, CA.

Goodman, D.S. and X. Zang (2008) The new rich in China: the dimensions of social change. In D.S. Goodman (ed.), The new rich in China: future rulers, present lives, Routledge, Abingdon, UK.

Gramsci, A. ([1966] 2005) The intellectuals. In S.P. Hier (ed.), Contemporary sociological thought: themes and theories. Canadian Scholar's Press, Toronto.

Hamnett, C. (1991) The blind men and the elephant: the explanation of gentrification.

Transactions of the Institute of British Geographers 16.2, 173-89

Harvey, D. (1981) The spatial fix-Hegel, von Thunen, and Marx. Antipode 13.3, 1-12.

Harvey, D. (2005) A brief history of neoliberalism. Oxford University Press, Oxford.

Hedin, K., E. Clark, E. Lundholm and G. Malmberg (2012) Neoliberalization of housing in Sweden: gentrification, filtering, and social polarization. Annals of the Association of American Geographers 102.2, 443-63.

Hudson, J., W. Hurst and C. Sorace (2010) Workers in post-socialist China: shattered rice bowls, fragmented subjectivities. In Y-W. Chu (ed.), Chinese capitalisms: historical emergence and political implications, Palgrave Macmillan, London.

Lan, P.C. (2014) Segmented incorporation: the second generation of rural migrants in Shanghai. The China Quarterly 217, 243-265.

Lees, L. (2008) Gentrification and social mixing: towards an inclusive urban renaissance? Urban Studies 45.12, 2449-70.

Lefebvre, H. ([1974] 1991) The production of space. Blackwell, Oxford, UK.

Ley, D. (2003) Artists, aestheticisation and the field of gentrification. Urban Studies 40.12, 2527-44.

Li, S.M. (2003) Housing tenure and residential mobility in urban China: a study of commodity housing development in Beijing and Guangzhou. Urban Affairs Review 38.4, 510-34.

This article is protected by copyright. All rights reserved. 
Liv, J. and H. Wang (2006) The origins of the general line for the transition period and of the acceleration of the Chinese socialist transformation in summer 1955. The China Quarterly 187, 724-31.

Logan, J. (ed.) (2008) Urban China in transition. Studies in Urban and Social Change, Blackwell, Oxford.

Magnani, E. and R. Zhu (2015) Social mobility and inequality in urban China: understanding the role of intergenerational transmission of education. Applied Economics 47.43, 4590606.

McAfee, A. and E. Brynjolfsson (2012) Big data: the management revolution. Harvard Business Review 90.10, 60-66.

McDowell, L., K. Ward, D. Perrons, K. Ray and C. Fagan (2006) Place, class and local circuits of reproduction: exploring the social geography of middle-class childcare in London. Urban Studies 43.12, 2163-82.

Mok, K.H., Y.C. Wong and X. Zhang (2009) When marketisation and privatisation clash with socialist ideals: educational inequality in urban China. International Journal of Educational Development 29.5, 505-12.

NSB (Nanjing Statistical Bureau) (2014) Statistical yearbook of Nanjing 2013. China Statistics Press, Beijing, China.

Nash, R. (1990) Bourdieu on education and social and cultural reproduction. British Journal of Sociology of Education 11.4, 431-47.

Nee, V. (1996) The emergence of a market society: changing mechanisms of stratification in China. American Journal of Sociology 101.4, 908-49

Newman, K. and E.K. Wyly (2006) The right to stay put, revisited: gentrification and resistance to displacement in New York City. Urban Studies 43.1, $23-57$.

Pinches, M. (1999) Culture and privilege in capitalist Asia. Routledge, London.

Power, S., T. Edwards and V. Wigfall (2003) Education and the middle class. McGraw-Hill Education, London.

Ramkissoon, H., L.D.G. Smith and B. Weiler (2013) Testing the dimensionality of place attachment and its relationships with place satisfaction and pro-environmental behaviours: a structural equation modelling approach. Tourism Management, 36, 55266.

Robson, G. and T. Butler (2001) Coming to terms with London: middle-class communities in a global city. International Journal of Urban and Regional Research 25.1, 70-86.

Rose, D. (2013) Rethinking gentrification: beyond the uneven development of Marxist urban theory. In J. Brown-Saracino (ed.), The gentrification debates: a reader, Routledge, Abingdon.

Rowe, E. (2014) Theorising geo-identity and David Harvey's space: school choices of the geographically bound middle-class. Critical Studies in Education 56.3, 285-300.

Sassen, S. (2014) Expulsions: brutality and complexity in the global economy. Harvard University Press, Cambridge, MA. 
Sewell, W.H. and R.M. Hauser (1972) Causes and consequences of higher education: models of the status attainment process. American Journal of Agricultural Economics 54.5, 85161.

Smith N. (1982) Gentrification and uneven development. Economic Geography 58.1, 139-55.

Smith, N. (1996) The new urban frontier: gentrification and the revanchist city. Routledge, London.

Smith, N. (2002) New globalism, new urbanism: gentrification as global urban strategy. Antipode 34.3, 427-50.

Soja, E.W. (1996) Thirdspace: journeys to Los Angeles and other real-and-imagined places. Blackwell, Oxford.

Sullivan, A. (2001) Cultural capital and educational attainment. Sociology 35.4, 893-912.

Tomba, L. (2004) Creating an urban middle class: social engineering in Beijing. The China Journal 51, 1-26.

Waters, D., T. Waters, E. Hahnke, M. Lippke, E. Ludwig-Glück, D. Mai, N. Ritzi-Messner, C. Veldhoen and L. Fassnacht (2010) The distribution of power within the community: classes, Stände, parties. Journal of Classical Sociology 10.2, 137-52.

Waters, J. and R. Brooks (2010) Accidental achievers? International higher education, class reproduction and privilege in the experiences of UK students overseas. British Journal of the Sociology of Education 31.2, 217-28.

Willis, P. (1977) Learning to labour: how working class kids get working class jobs. Columbia University Press, New York, NY.

Willis, P. (1981) Cultural production is different from cultural reproduction is different from social reproduction is different from reproduction. Interchange 12.2/3, 48-67.

Wilson, R.A. and D.A. Schulz (1978) Urban sociology. Prentice Hall, Englewood Cliffs, NJ.

Wong, L. (2004) Market reforms, globalization and social justice in China. Journal of Contemporary China 13.38, 151-71.

Wu, F. (2016) State dominance in urban redevelopment: beyond gentrification in urban China. Urban Affairs Review 52.5, 631-58.

Wu, F. and C.J. Webster (2010) Marginalization in urban China: comparative perspectives. Palgrave Macmillan, London.

Wu, Q., J. Cheng, G. Chen, D.J. Hammel and X. Wu (2014) Socio-spatial differentiation and residential segregation in the Chinese city based on the 2000 community-level census data: a case study of the inner city of Nanjing. Cities 39, 109-19.

Wu, Q., X. Zhang and P. Waley (2016) Jiaoyufication: when gentrification goes to school in the Chinese inner city. Urban Studies 53.16, 3510-26.

Wu, Q., X. Zhang and P. Waley (2017) When Neil Smith met Pierre Bourdieu in Nanjing, China: bringing cultural capital into rent gap theory. Housing Studies 32.5, 659-77.

Zhou, X., P. Moen and N.B. Tuma (1998) Educational stratification in urban China: 1949-94. Sociology of Education 71.3, 199-222. 


\section{$<$ UNNUMBERED FOOTNOTE TO GO AT FOOT OF FIRST PAGE>}

The research for this article was supported by the National Natural Science Foundation of China (No: 41671155 and 41271176) and the Service Center for the Floating Population, 'The dynamic monitoring of the floating population survey in $2015^{\prime}$. The authors would particularly like to thank interviewees and participants who live among the jiaoyufication of Nanjing, China and Vancouver, Canada, as well as Dr Chunhui Liu for data processing; without their help this article could not have been written. We would also like to express our thanks to the anonymous IJURR reviewers for their helpful comments.

\section{$<$ NUMBERED FOOTNOTES > \\ $<$ FN1>See: http://www.statisticssolutions.com/amos/}

$<\mathrm{FN} 2>$ Based on the Temporary Act of Management of the Compulsory Education Schools, Secondary School and Colleges Charge issued in 1996. The State Education Commission, State Development Planning Commission, Ministry of Finance and other related departments admitted the incidental expenses paid by students at the compulsory education stage. These included a 'temporary schooling fee' paid by students who temporarily study in a region in which their permanent residence is not registered, a 'choice fee' paid by students who choose a school zone in which they are not registered to study by hukou registration, or an 'increase enrolment fee' paid by students who are enrolled when a school requests the local educational authority to increase its enrolment. 
<FIGURE CAPTIONS: Typesetter: please refer to instructions in FIGS 1-4 Word file>

<FIGURE 1 CAPTION>

Figure 1 Displacement and replacement in the production of jiaoyufied space (source:

devised by J. Cheng and Q. Wu)

$<$ FIGURE 2 CAPTION>

Figure $\mathbf{2}$ Location of case study area and selected key schools in Nanjing city centre (photos by Qiyan Wu)

$<$ FIGURE 3 CAPTION>

Figure 3 Conceptual model of living conditions (hypotheses 1 to 4 , left) and higher education (hypotheses 5 to 8 , right) (source: devised by J. Cheng and $\mathrm{Q}$. Wu)

<FIGURE 4 CAPTION>

Figure 4 Results of the higher-education structural models A and B (source: devised by J. Cheng and $\mathrm{Q}$. Wu) 
$<\mathrm{H}_{1}>$ APPENDIX-Basic statistics of the surveyed cases $\left\langle/ \mathrm{H}_{1}\right\rangle$

\begin{tabular}{|c|c|c|c|}
\hline Sample Attribute & & Size & Ratio (\%) \\
\hline \multirow[t]{2}{*}{ Gender } & Female & 630 & 52 \\
\hline & Male & 583 & 48 \\
\hline \multirow[t]{4}{*}{ Age } & $23-26$ & 292 & 24 \\
\hline & $27-30$ & 346 & 29 \\
\hline & $31-34$ & 336 & 28 \\
\hline & $35-38$ & 239 & 20 \\
\hline \multirow[t]{4}{*}{ Degree } & Associate & 276 & 23 \\
\hline & Bachelor & 778 & 64 \\
\hline & Master & 144 & 12 \\
\hline & $\mathrm{PhD}$ & 15 & 1 \\
\hline \multirow[t]{2}{*}{ Graduation year } & Before 2008 & 749 & 62 \\
\hline & After 2008 & 464 & 38 \\
\hline \multirow[t]{7}{*}{ Income } & $\leq 1,500$ & 17 & 1 \\
\hline & $1,501-3,000$ & 139 & 11 \\
\hline & $3,001-6,000$ & 554 & 46 \\
\hline & $6,001-9,000$ & 311 & 26 \\
\hline & $9,001-12,000$ & 105 & 9 \\
\hline & $12,001-15,000$ & 48 & 4 \\
\hline & $\geq 15,001$ & 39 & 3 \\
\hline
\end{tabular}

NOTE: Age and income were closed questions in our survey.

SOURCE: Authors' own findings (2015)

This article is protected by copyright. All rights reserved. 
$<$ Figures will need redrawing to be consistent with IJURR style. Figure 2 needs re-composing. Component parts of figures (photos, maps) to be (have been?) supplied>

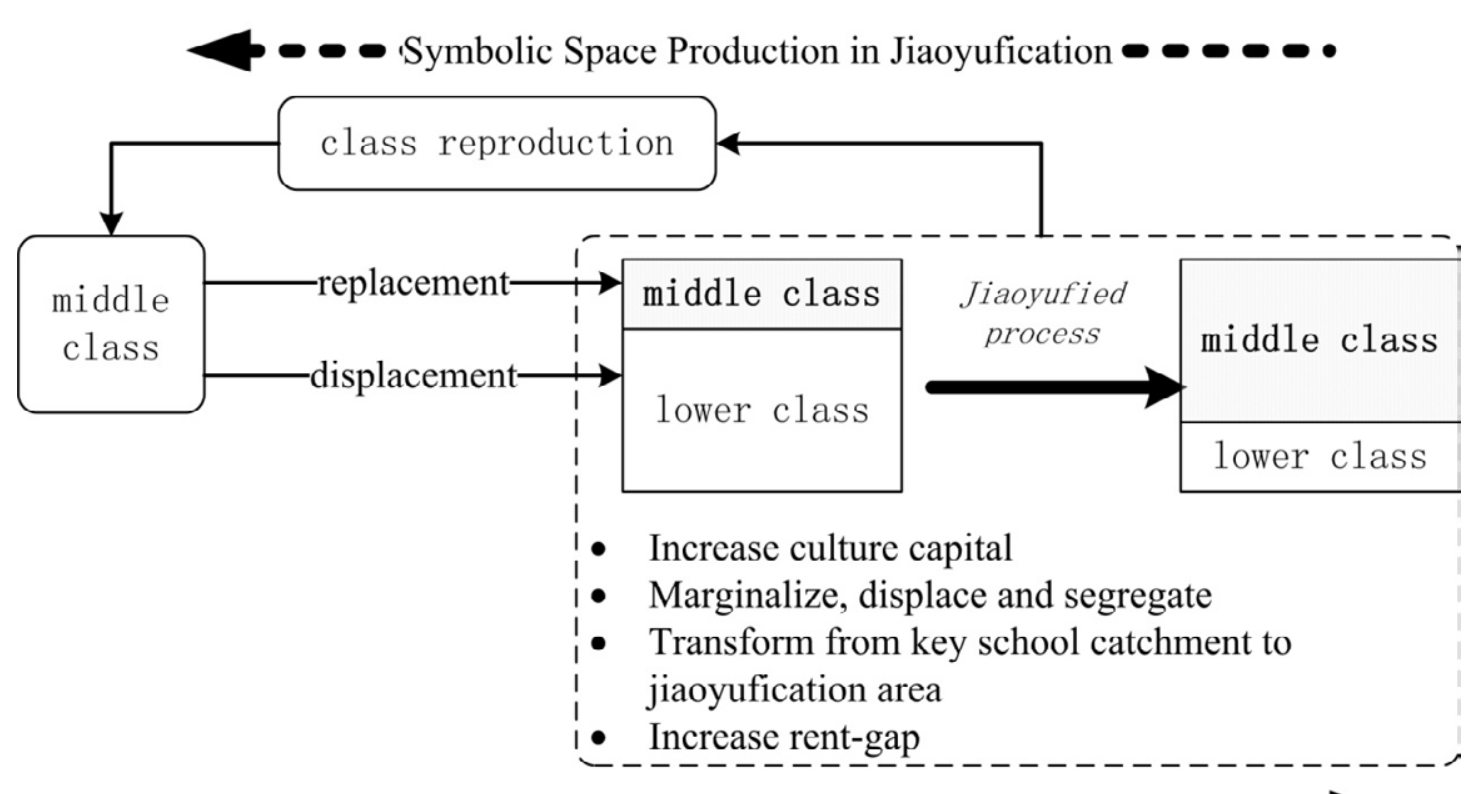

Figure 1 Displacement and replacement in the production of jiaoyufied space (devised by Jianquan Cheng and Qiyan Wu) $<$ Typesetter: Increase cultural capital etc. becomes:

Increased cultural capital

Marginalization, displacement and segregation

Transformation from key school catchment to jiaoyufication area

Increased rent-gap>

This article is protected by copyright. All rights reserved. 


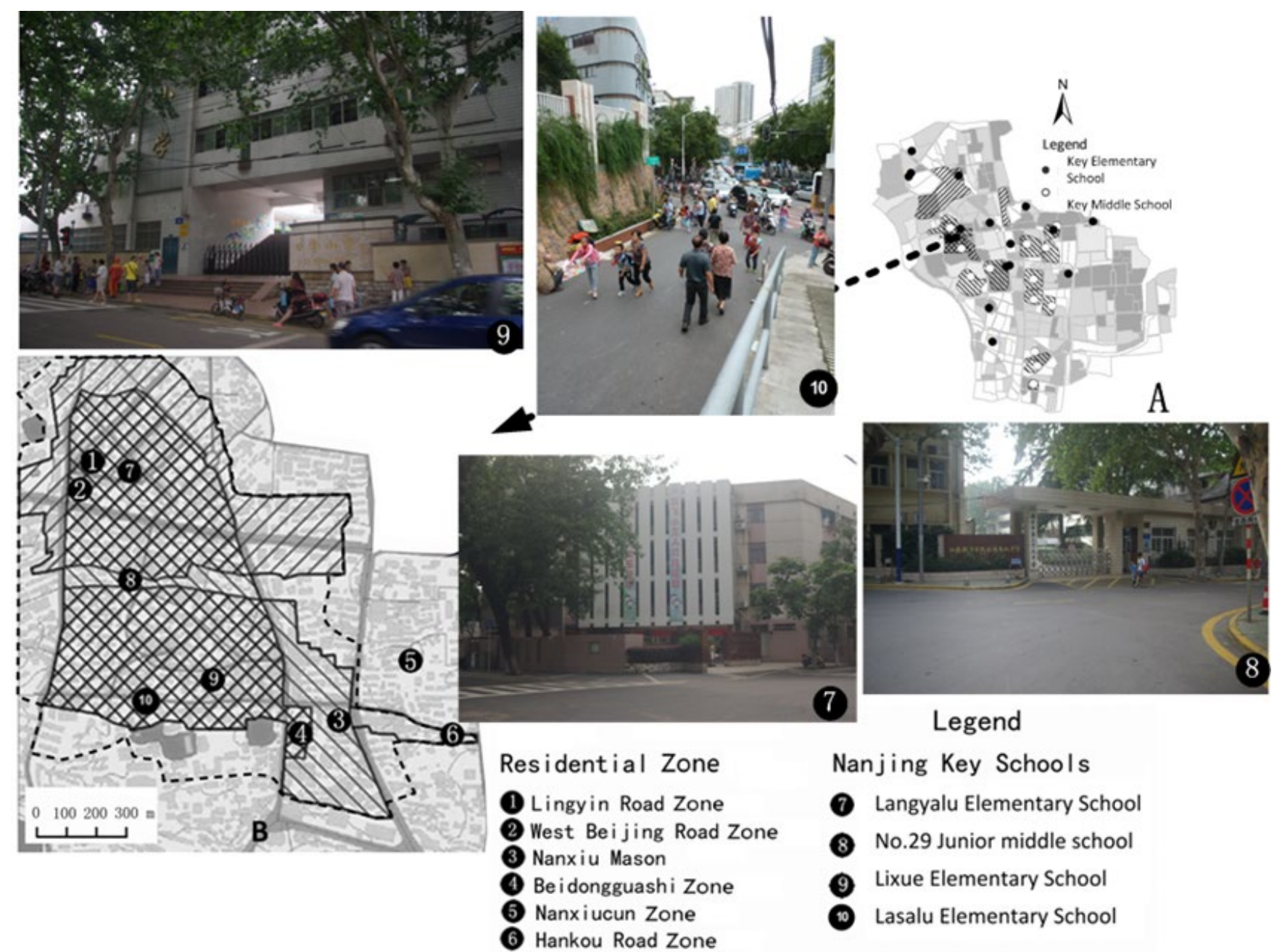

Figure $\mathbf{2}$ Location of case study area and selected key schools in Nanjing city centre (photos by Qiyan Wu)

This article is protected by copyright. All rights reserved. 


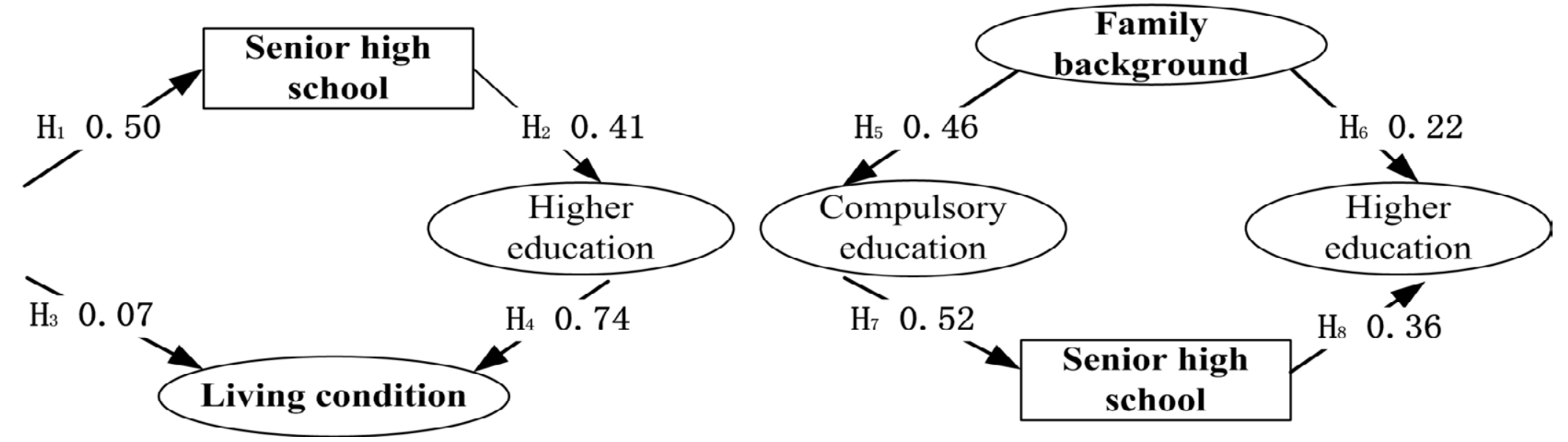

Figure 3 Conceptual model of living conditions (hypotheses 1 to 4 , left) and higher education (hypotheses 5 to 8 , right) (devised by Jianquan Cheng and Oiyan Wu)

$<$ Typesetter: Please change text in bottom left oval to Living conditions. Please also improve the setting of the diagram by redrawing it, consistent in style with Figure 4. It is important to keep the oval and oblong shapes intact> 


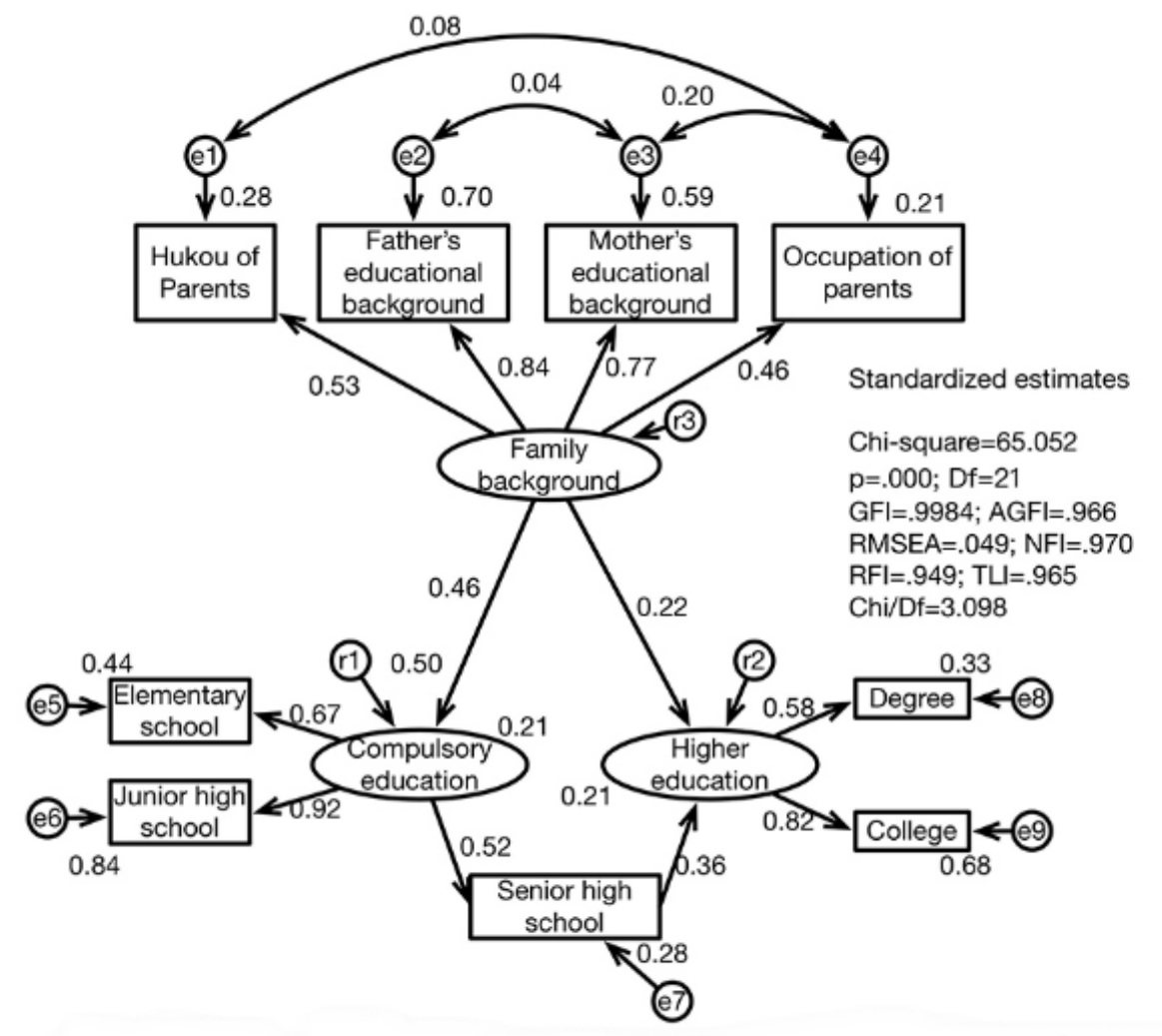

(A)

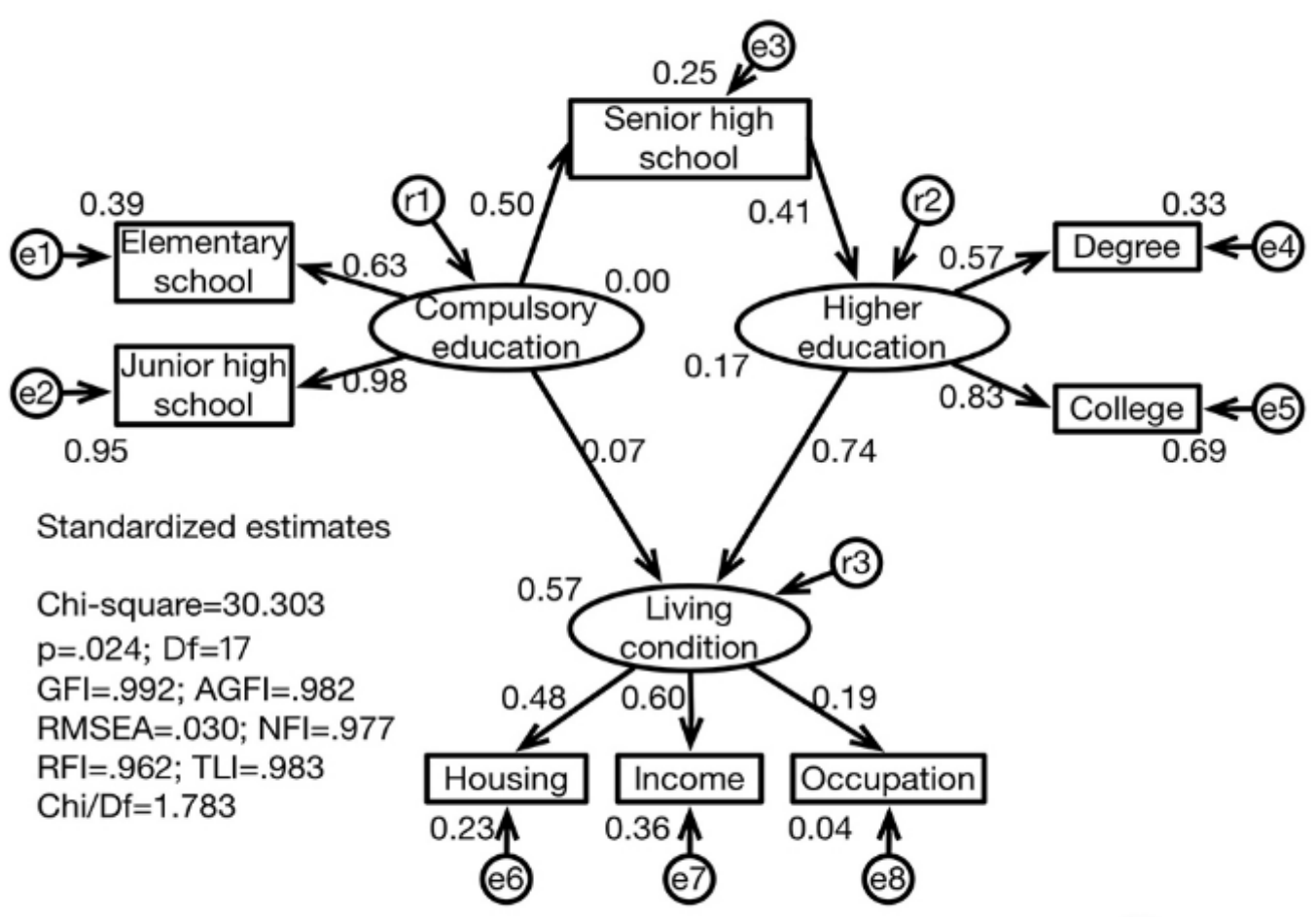

(B)

Figure 4 Results of the high-education structural models A and B (devised by Jianquan Cheng and Qiyan Wu)

$<$ Typesetter: Please change text in bottom right oval to Living conditions. Please also improve the setting of the diagram by redrawing it, consistent in style with Figure 3> 


\section{University Library}

\section{- M M N E R VA A gateway to Melbourne's research publications}

Minerva Access is the Institutional Repository of The University of Melbourne

Author/s:

Wu, Q;Edensor, T;Cheng, J

Title:

Beyond Space: Spatial (Re)Production and Middle-Class Remaking Driven by Jiaoyufication in Nanjing City, China

Date:

2018-01-01

Citation:

Wu, Q., Edensor, T. \& Cheng, J. (2018). Beyond Space: Spatial (Re)Production and Middle-Class Remaking Driven by Jiaoyufication in Nanjing City, China. INTERNATIONAL JOURNAL OF URBAN AND REGIONAL RESEARCH, 42 (1), pp.1-19. https:// doi.org/10.1111/1468-2427.12568.

Persistent Link:

http://hdl.handle.net/11343/283563 